that the sun is only once that of water. What the sun is he could not tell, but it is a very poor light creature indeed. The density of Mercury is perhaps rather greater than that of the earth. The density of Venus is much the same as that of the earth, and the density of Mars is also much the same as that of the earth. Then after that comes a shower of little planets, about 200 of which have been observed up to the present time, and he could not tell what they are made of. Then there are Jupiter and Saturn, which are no heavier than water. So that it appears clear that, assuming the formation of these things by the condensation of nebulæ, on the theory he had mentioned, the different parts of the nebulæ which have contributed to the solar system are very different. Well, that being considered as established, it follows that in the constitution of our earth there may be parts of very different density. He should say that the high and prominent parts of the land are made of something light, and the heavy and dense parts are those covered by a considerable quantity of water, which have sunk deep into the central lava on which, he conceived, all things are resting.

And now he had come pretty nearly to the end of his theory, and he would show them what he feared they would call an absurd representation of what he conceived the state of the earth to be. [The lecturer drew attention to a diagram of an "ideal earth," roughly showing his theory-some parts of the crust of the earth being thick and coloured darkly to indicate density; some thick and not so dense, and all admitting of volcanic eruptions from the interior, which was represented as lava.] Remember that everything here is exaggerated. It is not intended to be a correct representation. It is a caricature of the most extravagant kind; but if it conveyed to them the broad ideas that had impressed themselves upon his mind, it would be doing the right thing. He thought a large proportion of the centre of the earth is fluid and hot, and he thought that upon this there were certain divers classes of something like solid matter. In all these parts there are cracks or chinks through which volcanoes burst out where the cover of the earth is very thin. In some places you have two or three volcanoes together. There is one instance in Europe, where we have Etna, Stromboli, and Vesuvius. In this diagram he had condensed to the best of his conjectural power his supposition as to what the state of the earth really is; and if any one chose to find fault with it he would not quarrel with him. He only gave it as a sort of inference from a number of things he had said.

\section{A NEW INSULATING STAND}

SIR WILLIAM THOMSON has frequently dwelt on the great importance of insulating, with the utmost care, any apparatus intended for researches relating to static electricity; he has shown that the atmosphere and other gases have but little effect in dissipating an electric charge, even when moist, and that it escapes mainly in consequence of the deposition of a layer of moisture upon the insulating supports which renders their surface conducting. In all Sir W. Thomson's electrometers there is an arrangement for drying the insulating surfaces by means of sulphuric acid, either free or absorbed by pumice. This method admits of very general application :--Any body, as for example apparatus constructed for the observation of atmospheric electricity, may be most perfectly insulated by supporting it on glass rods inserted in glass cylinders containing free sulphuric acid or pumice moistened with it. In order to do this the lower end of the rods must be either inserted into cylinders of lead or else fixed to the bottom of the jar by means of a substance not acted upon by sulphuric acid, for example, melted sulphur or paraffin; melted sulphur is liable, on account of its temperature, to crack the jars,

${ }^{I}$ By M. E. Mascart, Professor of Physics, Collége de France, Paris. notwithstanding the precaution of previous heating; paraffin, on the other hand, softens in the course of time, and the glass rods do not retain their vertical position. Notwithstanding these disadvantages excellent insulators may be thus extemporised as occasion may require.

For permanent use it is advantageous to employ insulators specially constructed, as shown in the accompanying figure; it consists of a bottle having a narrow neck,

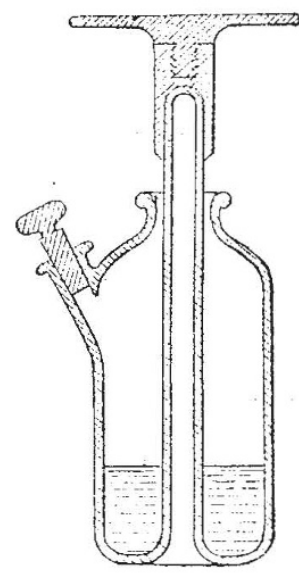

through which passes a tubular continuation of the bottom, about $4 \mathrm{~mm}$. less in diameter than the internal diameter of the neck, so as to leave a space of $2 \mathrm{~mm}$. (about) between them. The top of this hollow rod is closed, in order that a brass tube may be cemented upon it, into which may be screwed any apparatus, as, for example, a disc as shown in the figure, a sphere, a crutch on a hoop, \&c., \&c. In the shoulder of the bottle is a neck, closed with a ground-glass stopper, through which sulphuric acid may be poured, in the first instance, and renewed from time to time. As the space between the hollow rod and the neck of the bottle is very small, the air in the bottle does not change very rapidly, and the sulphuric acid remains efficient for a long time. It is only necessary to run off a portion of it occasionally by means of a siphon, and to add fresh; as this may be done without disturbing the apparatus, the insulation may be maintained for any length of time. Moreover, for an insulator to be used occasionally, an addition is made of a vulcanised rubber cap, which slides on the glass rod to close the neck of the bottle when not in use. ${ }^{1}$

A double pendulum of pith balls supported by such an apparatus maintains its divergence, after being charged with electricity, for a very long time, even in a theatre filled with an audience. One may show by a simple experiment the great efficacy of this apparatus in comparison with insulators of glass exposed to the air, even when carefully varnished with shellac. If a pair of pith balls, suspended by a thread of cotton, is hung upon the latter support, and the metallic foot is placed on an insulator, and connected with a charged condenser, no divergence of the pith balls occurs in the first instance, but little by little the electricity is propagated along the glass rod, and then the threads near the support begin to separate, and soon after the balls diverge and remain at a certain distance from each other.

The electrometers of Sir Wm. Thomson are sometimes so perfectly insulated that the loss of a charge of electricity does not amount to $\pi_{0}^{\frac{1}{0}} \pi^{\text {th }}$ part in twenty-four hours. By means of the insulator described above, one may obtain an insulation of like order for bodies supported in the open air, and thus diminish to a great extent one of the chief sources of error usually met with in experimenting with static electricity.

These may be obtained of various sizes, one litre, half-litre, quarterlit:e capacity, at Alvergniat Frères, ro, Rue de !a Sorbonne, Paris. 